\title{
Circulating tumor DNA: Solid data from liquid biopsies
}

\author{
David S. Schrump, MD, MBA
}

\footnotetext{
From the Thoracic Epigenetics Section, Thoracic and GI Oncology Branch, Center for Cancer Research, National Cancer Institute, Bethesda, Md.

Disclosures: Author has nothing to disclose with regard to commercial support.

Received for publication May 12, 2017; accepted for publication May 18, 2017; available ahead of print June 16, 2017.

Address for reprints: David S. Schrump, MD, MBA, Thoracic Epigenetics Section, Thoracic and GI Oncology Branch, Center for Cancer Research, National Cancer Institute, Bethesda, MD 20892 (E-mail: David_Schrump@nih.gov).

J Thorac Cardiovasc Surg 2017;154:1132-3

0022-5223/\$0.00

Published by Elsevier Inc. on behalf of The American Association for Thoracic Surgery

http://dx.doi.org/10.1016/j.jtcvs.2017.05.059
}

Cell-free DNA (cfDNA) initially was discovered in human blood in 1948. ${ }^{1}$ It is now well established that levels of cfDNA are elevated significantly in patients with cancer as a result of apoptosis and necrosis of tumor cells and secretion of DNA in tumor exosomes. During recent years, cfDNA has attracted considerable attention as a potential noninvasive means to establish diagnosis and prognosis of patients with cancer with diverse histologies. ${ }^{2}$ Furthermore, given its short half-life, cfDNA has emerged as an attractive and reliable means to monitor treatment responses in patients with cancer. ${ }^{3-5}$ Although levels of circulating tumor DNA (ctDNA) vary among patients with cancer with similar tissue histology and stage due to extent of necrosis, hypoxia, and blood supply in their respective neoplasms, there is good correlation between ctDNA levels, tumor burden, and stage of disease. ${ }^{2}$ The rapid development of next-generation sequencing technologies combined with improved techniques for isolation of ctDNA has led to approval by the Food and Drug Administration of epidermal growth factor receptor mutation analysis of ctDNA for precision therapy of patients with lung cancer. ${ }^{6}$

In the present study, Chen and colleagues ${ }^{7}$ used nextgeneration sequencing techniques and a 50 cancer gene panel to prospectively compare DNA mutation profiles in early-stage and locally advanced lung cancers and matched plasma samples in 76 patients undergoing potentially curative resections. They observed an overall concordance of $68 \%$. In contrast to other studies, ${ }^{3}$ concordance did not depend on patients' smoking status or overall mutation

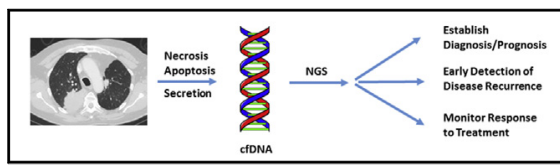

Evaluation of circulating tumor DNA: an evolving paradigm for precision cancer therapy.

Central Message

Circulating tumor DNA provides a noninvasive method to diagnose and monitor disease burden in lung cancer patients. It will soon become a standard of care.

See Article page 1123 .

burden of the primary tumors but, consistent with other published studies, ${ }^{2,8}$ was associated significantly with increased clinical stage. A total of 24 patients had discordant tumor:plasma DNA mutation results, most likely secondary to heterogeneity of the primary tumors in the cases of negative tumor:positive ctDNA results, or very limited disease burden in these patients with mutations identified in tumor DNA but not plasma. Overall, the results are comparable with those reported by Guo and colleagues, ${ }^{8}$ who used similar sequencing methods and observed a concordance of $78 \%$, specificity of $69 \%$, and sensitivity of $93 \%$ in 41 patients with lung cancer undergoing surgery. Not surprisingly, these authors ( 2 of whom are coauthors in the present study) also observed that ctDNA outperformed serum markers in the detection of lung cancer.

This study adds to a growing number of reports pertaining to the feasibility and reliability of ctDNA for determining diagnosis and prognosis as well as monitoring responses to treatment in patients with lung cancer (Figure 1). ${ }^{2-5,8}$ The authors are to be commended for rapid accrual to this very interesting study. Limitations of this study include the relatively low concordance rate for early stage (T1a) lung cancers; reliable liquid biopsies in patients with early-stage
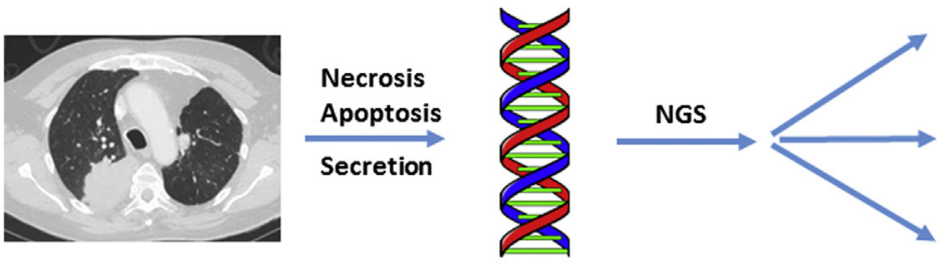

Establish

Diagnosis/Prognosis

Early Detection of

Disease Recurrence

Monitor Response

to Treatment

cfDNA

FIGURE 1. Evaluation of circulating tumor DNA: An evolving paradigm for precision cancer therapy. $c f D N A$, Cell-free DNA; NGS, next generation sequencing. 
lung cancers could obviate invasive and sometimeschallenging procedures to establish tissue diagnosis. Implementation of DNA amplification techniques might increase sensitivity of ctDNA analysis, and it would be interesting if the authors could examine this issue in future experiments. In addition, the examination of methylated genes in ctDNA,, 10 such as secretin, which is methylated in nearly $100 \%$ of lung cancers (including very early lesions), ${ }^{11}$ may improve the sensitivity of ctDNA for detection/diagnosis of patients with lung cancer. Unquestionably, this technology will continue to evolve and will rapidly become part of the armamentarium of thoracic surgeons and medical oncologists involved in precision therapy of lung cancer.

\section{References}

1. Mandel P, Metais P. Les acides nucleiques du plasma sanguin chez l'homme [in French]. C R Seances Soc Biol Fil. 1948;142:241-3.

2. Wan JC, Massie C, Garcia-Corbacho J, Mouliere F, Brenton JD, Caldas C, et al. Liquid biopsies come of age: towards implementation of circulating tumour DNA. Nat Rev Cancer. 2017;17:223-38.
3. Yang M, Topaloglu U, Petty WJ, Pagni M, Foley KL, Grant SC, et al. Circulating mutational portrait of cancer: manifestation of aggressive clonal events in both early and late stages. J Hematol Oncol. 2017;10:100.

4. Yeung KT, More S, Woodward B, Velculescu V, Husain H. Circulating tumor DNA for mutation detection and identification of mechanisms of resistance in non-small cell lung cancer. Mol Diagn Ther. March 24, 2017 [Epub ahead of print].

5. Cabel L, Riva F, Servois V, Livartowski A, Daniel C, Rampanou A, et al. Circulating tumor DNA changes for early monitoring of anti-PD1 immunotherapy: a proof-of-concept study. Ann Oncol. April 29, 2017 [Epub ahead of print].

6. U.S. Food and Drug Administration. FDA approves first blood test to detect gene mutation associated with non-small cell lung cancer. Available at: https://www.fda.gov/ NewsEvents/Newsroom/PressAnnouncements/ucm504488.htm. Accessed May 10, 2017.

7. Chen K, Zhang J, Guan T, Yang F, Lou F, Chen W, et al. Comparison of plasma to tissue DNA mutations in surgical non-small cell lung cancer patients. J Thorac Cardiovasc Surg. 2017;154:1123-31.e2.

8. Guo N, Lou F, Ma Y, Li J, Yang B, Chen W, et al. Circulating tumor DNA detection in lung cancer patients before and after surgery. Sci Rep. 2016;6:33519.

9. Lu Y, Li S, Zhu S, Gong Y, Shi J, Xu L. Methylated DNA/RNA in body fluids as biomarkers for lung cancer. Biol Proced Online. 2017;19:2.

10. Lissa D, Robles AI. Methylation analyses in liquid biopsy. Transl Lung Cancer Res. 2016;5:492-504.

11. Zhang YA, Ma X, Sathe A, Fujimoto J, Wistuba II, Lam S, et al. Validation of SCT methylation as a hallmark biomarker for lung cancers. J Thorac Oncol. 2016;11:346-60. 